\title{
Fourth Molars in the Anthropoidea
}

\author{
Daris R. Swindler \\ Department of Anthropology, University of Washington, Seattle, WA 98195 U.S.A
}

ABSTRACT Fourth molars are not common in the anthropoidea. Orangutans possess the highest frequencies $(7-13 \%)$ while many genera in the suborder lack the fourth molars. A review of the incidence of M4's in

Polydontia (extra teeth) are found in both extinct (Jungers and Gingerich, 1980) and extant primate taxa (Colyer 1936; Krapp and Lampel, 1973; Lavelle and Moore, 1973; Miles and Grigson, 1990; Schultz, 1935). But as Jungers and Gingerich (1980:1) mentioned in their investigation, "the developmental basis of extra teeth in a particular tooth category remains obscure." Several explanations have been proffered through the years regarding the development of fourth molars, e.g., distal growth of the dental lamina, duplication of the M3 tooth germ and atavism (see in particular Jungers and Gingerich, 1980; Miles and Grigson, 1990). The fourth molar is a rarity in the genus Macaca. In an ongoing longitudinal study of dental development in Macaca nemestrina $\mathrm{M}_{4}$ and $\mathrm{M}^{4}$ were observed radiographically in a male specimen. Development of the M4 is discussed and the appearance and frequency of M4's in the Anthropoidea is reviewed.

\section{MATERIALS AND METHODS}

The parental generation was collected from freeranging populations in Sumatra and transported to the National Primate Research Center at the University of Washington. These animals were the breeding colony of the animals in the longitudinal growth and development study (Sirianni and Swindler, 1985). After weaning, between 3 and 8 months, the animals were raised and housed separately with their age mates. Radiographs of the head in norma lateralis were taken on a regular schedule from about three months to seven years. There were a total of 140 animals in the study, 70 females and 70 males. Tables 1, 2 and 3 present the number of specimens with M4's except for the figures presented of Selenka (1898), Hrdli $\square$ ka (1907) and Hooijer (1948) in Table 2 that record the total number of M4's

\section{RESULTS AND DISCUSSION}

The M4 was observed in the radiograph of one male and was present in both the maxilla and mandible. Thus of a total sample of 140 Macaca nemestrina $0.7 \%$ showed this condition (Table 1). A slightly lower percentage has been reported for the presence of M4 for the genus Macaca by Miles and Grigson, $0.2 \%$ of 901 animals (1990), Lavelle and Moore (1973) recorded 0.3\% for 350 Macaca the Anthropoidea is presented and a description of the ontogeny of M4 in Macaca nemestrina is described and offered as an explanation of the development of M4's in this taxon.

TABLE 1. Incidence of M4's in the Cercopithecidae

\begin{tabular}{lrrc}
\hline \multicolumn{1}{c}{ Genus } & $\begin{array}{c}\text { Number of } \\
\text { Specimens }\end{array}$ & M4 & Percent \\
\hline Colobus $^{1}$ & 1,485 & 22 & 4.00 \\
Colobus $^{2}$ & 140 & 0 & 0.00 \\
Colobus $^{8}$ & 155 & 5 & 3.23 \\
Presbytis $^{1 *}$ & 289 & 1 & 0.30 \\
Presbytis $^{2}$ & 100 & 0 & 0.00 \\
Presbytis $^{8}$ & 321 & 1 & 0.31 \\
Pygathrix $^{1}$ & 16 & 0 & 0.00 \\
Rhinopithecus $^{1}$ & 17 & 0 & 0.00 \\
Rhinopithecus $^{3}$ & 11 & 1 & 9.10 \\
Simias $^{1}$ & 10 & 0 & 0.00 \\
Nasalis $^{1}$ & 83 & 0 & 0.00 \\
Cercopithecus $^{1}$ & 1,823 & 10 & 0.50 \\
Cercopithecus $^{2}$ & 350 & 4 & 1.10 \\
Cercopithecus $^{8}$ & 2,460 & 16 & 0.65 \\
Erythropithecus $^{1}$ & 95 & 3 & 3.20 \\
Erythropithecus $^{8}$ & 95 & 2 & 2.11 \\
Cercocebus $^{1}$ & 311 & 0 & 0.00 \\
Papio $^{1}$ & 410 & 2 & 0.50 \\
Papio $^{2}$ & 38 & 1 & 2.60 \\
Papio $^{8}$ & 541 & 6 & 1.11 \\
Mandrillus $^{1}$ & 56 & 0 & 0.00 \\
Theropithecus $^{1}$ & 7 & 0 & 0.00 \\
Macaca $^{1}$ & 901 & 2 & 0.20 \\
Macaca $^{4}$ & 140 & 1 & 0.70 \\
Macaca $^{2}$ & 350 & 1 & 0.30 \\
Macaca $^{8}$ & 2,379 & 9 & 0.38 \\
\hline Mries and $^{8}$ & & &
\end{tabular}

${ }^{1}$ Miles and Grigson (1990) $\left(\mathrm{M}^{4}\right.$ and $\left.\mathrm{M}_{4}\right)$

${ }^{2}$ Lavelle and Moore (1973) $\left(\mathrm{M}^{4}\right.$ and $\left.\mathrm{M}_{4}\right)$

${ }^{3}$ Hooijer(1952) $\left(\mathrm{M}^{4}\right)$

${ }^{4}$ This paper $\left(\mathrm{M}^{4}\right.$ and $\left.\mathrm{M}_{4}\right)$

${ }^{8}$ Krapp and Lampel (1973) (M $\mathrm{M}^{4}$ and $\left.\mathrm{M}_{4}\right)$

*P. entellus and vetulus groups

Daris R. Swindler, Department of Anthropology, University of Washington, Seattle, WA 98195 U.S.A.

E-mail: dswindle@u.washington.edu 


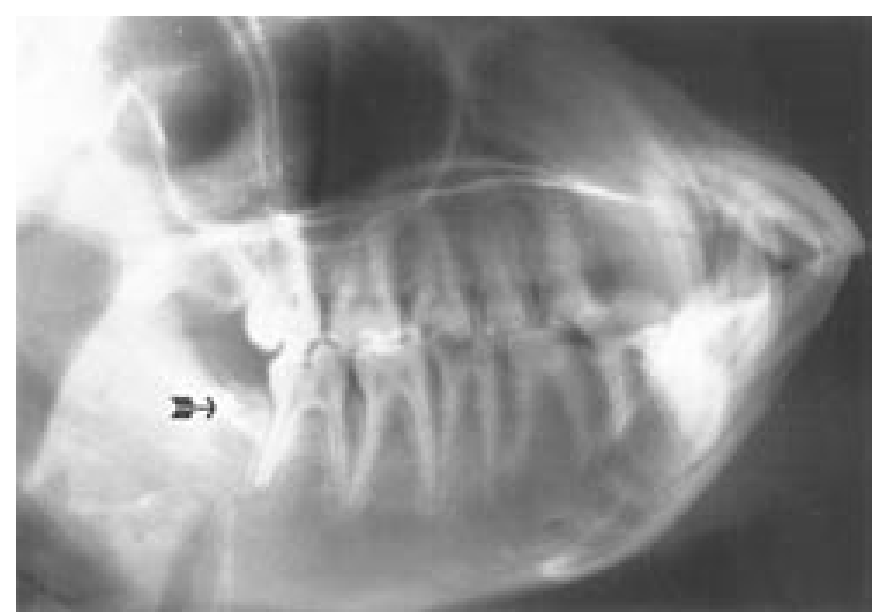

Fig. 1. Macaca nemestrina 6.2 years old. $\mathrm{M}_{4}$ crown visible within its crypt distal to $\mathrm{M}_{3}$. An interdental bony septum separates $M_{4}$ from $M_{3}$.

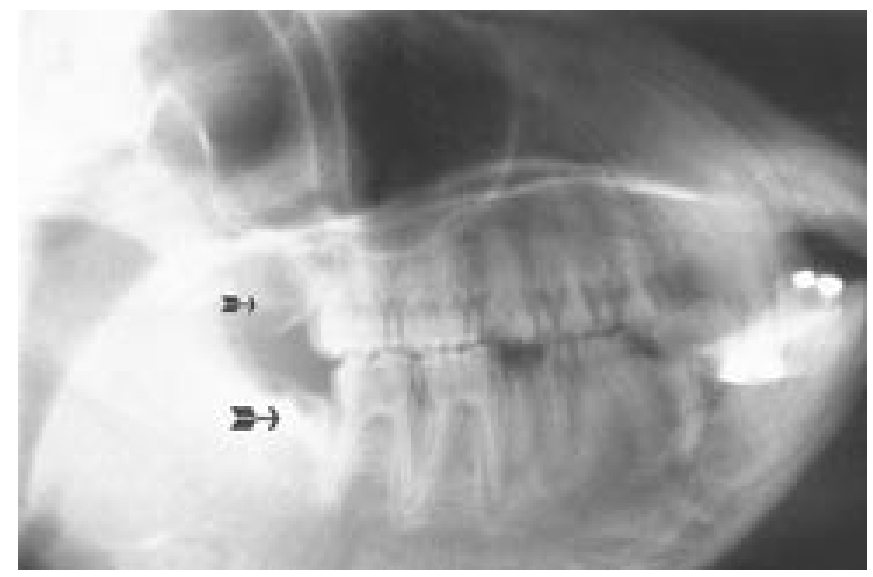

Fig. 2. Macaca nemestrina 7.0 years old. $\mathrm{M}_{4}$ crown complete and initial emergence has begun. There appears to be initial mineralization of $\mathrm{M}^{4}$ within a crypt.

as having total polygenesis but did not designate which teeth were involved. Krapp and Lampel (1973), in their comprehensive study of dental anomalies of living anthropoidea, found $0.38 \%$ of 2,379 macaque specimens with fourth molars.

The presence of extra teeth is low in all living cercopithecids irrespective of the tooth group, and it is interesting to note that most investigations have found a higher incidence of M4's in the subfamily Cercopithecinae than in the Colobinae, (Table 1). A notable exception to this finding is the $9.1 \%$ presence in Rhinopithecus; however, that figure represents one specimen out of a total of only eleven animals (Table 1). Of all the genera depicted in Tables 1, 2 and 3, Pongo has the highest frequency of M4 while colobines and New World monkeys generally have the lowest frequencies. Among living primates, Pongo is generally reported to have the highest percentage of M4's (Tables
1, 2 and 3). Gibbons appear to lack development of M4, a fact that has been known since the work of Bateson (1894) as reported in Miles and Grigson (1990). Also, several different genera of both New and Old World monkeys lack the 0ccurrence of M4. The taxonomic presence of M4's in the living Anthropoidea seems to lack any discernible correlation with body mass or facial prognathism since the M4 condition appears in primates ranging in size from gorillas to squirrel monkeys and in primates with both long and short snouts.

The aetiology of polydontia is uncertain. Earlier literature suggested that such occurrences were the result of atavism, although today the term has lost favor in most scientific circles. The heritability of the condition is not completely understood (Finn, 1967); however, there is evidence indicating that polydontia appears more often in isolated populations, and especially among some domesticates, which has suggested thethe involvement of genetic drift as a possible cause to Miles and Grigson (1990).

"Connate teeth" is an anomaly; that is, double teeth, incomplete dichotomy, or syndonty that should be reserved for teeth that are "developed or born together" (Miles and Grigson, 1990; Winkler and Swindler, 1993; Drusini and Swindler, 1994).

In the present case, both the upper and lower M4 would seem to represent the continued distal growth of the dental lamina in that M4 appears distally to the formation of M3. The development of $M_{4}$ will be discussed since it is more easily observed and it is assumed that $\mathrm{M}^{4}$ passed through similar developmental stages. The dental follicle and $\mathrm{M}_{4}$ appear between 5.5 and 6.2 years. At 6.2 years the crown is present, the cusps are connected but the crown is not complete and it is inclined obliquely at about $45^{\circ}$ to the occlusal plane (Fig. 1). There is no root development and the cleft has not yet formed, and as seen in this radiograph, an interdental septum separates $\mathrm{M}_{3}$ and $\mathrm{M}_{4}$ (Fig.1). In Fig. 2, (7.0 years), the crown appears nearly formed with beginning root formation while the crown is still inclined relative to the occlusal plane. The mesiodistal length of the crown is $8.5 \mathrm{~mm}$ which is about $3 \mathrm{~mm}$ shorter that the average size of $\mathrm{M}_{3}$ in male $M$. nemestrina $(10.9 \mathrm{~mm})$ and about equal in length to $M_{2}(8.6 \mathrm{~mm})$ (Swindler, 2002). Thus, this $\mathrm{M}_{4}$ is within the normal mesiodistal size range for molars of $M$. nemestrina. Unfortunately, this animal was not studied after 7 years of age so there is no information regarding the age of the animal when $\mathrm{M}_{4}$ emerged.

\section{CONCLUSION}

The presence of M4's is rare among living primates, particularly in gibbons, New World monkeys and colobine genera. The orangutans possess the highest frequency of M4's (7 to 13\%) of all living anthropoidea. The aetiology of M4's remains uncertain and may represent different developmental processes in different 
TABLE 2. Incidence of $M^{\prime}$ s in the Pongidae and Hylobatidae

\begin{tabular}{lccc}
\hline Genus & $\begin{array}{c}\text { Number of } \\
\text { Specimens }\end{array}$ & M4 & Percent \\
\hline Gorilla $^{1}$ & 546 & 22 & 4.00 \\
Gorrila $^{2}$ & 190 & 12 & 6.30 \\
Gorilla $^{8}$ & 1,409 & 56 & 4.00 \\
Pan $^{1}$ & 467 & 13 & 2.40 \\
Pan $^{2}$ & 100 & 2 & 2.00 \\
Pan $^{8}$ & 1,040 & 28 & 2.72 \\
Pongo $^{1}$ & 229 & 16 & 7.00 \\
Pongo $^{2}$ & 100 & 6 & 6.00 \\
Pongo $^{5}$ & 88 & 6 & 6.80 \\
Pongo $^{6}$ & 388 & 46 & 11.90 \\
Pongo $^{7}$ & 44 & 6 & 13.60 \\
Pongo $^{8}$ & 1,808 & 200 & 11.12 \\
Hylobates $^{1 *}$ & 391 & 3 & 0.80 \\
Hylobates $^{2}$ & 150 & 0 & 0.00 \\
Hylobates $^{8}$ & 1,276 & 9 & 0.71 \\
\hline
\end{tabular}

${ }^{1}$ Miles and Grigson (1990) $\left(\mathrm{M}^{4}\right.$ and $\left.\mathrm{M}_{4}\right)$

${ }^{2}$ Lavelle, and Moore (1973) $\left(\mathrm{M}^{4}\right.$ and $\left.\mathrm{M}_{4}\right)$

${ }^{5}$ Hooijer (1948) $\left(\mathrm{M}_{4}\right)$

${ }^{6}$ Selenka (1898) $\left(\mathrm{M}_{4}\right)$

${ }^{7}$ Hrdlička (1907) $\left(\mathrm{M}_{4}\right)$

${ }^{8}$ Krapp and Lampel (1973) $\left(\mathrm{M}^{4}\right.$ and $\left.\mathrm{M}_{4}\right)$

${ }^{*}$ Hylobates and Symphalangus

species. On the basis of the present specimen, it seems clear that $\mathrm{M}_{4}$ develops in a normal manner i.e., follicle, initial calcification, crown formation and root formation from a distal extension of the dental lamina, and that tooth formation takes place in a follicle distal to an interdental septum between it and $\mathrm{M}_{3}$.

\section{REFERENCES CITED}

Bateson W. 1894. Materials for the Study of Variation. London: Macmillian.

Colyer JF. 1936. Variations and diseases of the teeth of animals. London: John Bale, Sons \& Danielsson.

Drusini AG, Swindler DR. 1994, Connate incisors in a Pre-Columbian mandible from Nasca, Peru. Dental Anthropology Newsletter 9:11.

Hooijer DA. 1948. Prehistoric teeth of man and the orang-utan from central Sumatra, with notes on the fossil orang-utan from Java and southern China. Zoologische Mededeelingen Museum, Leiden, 29: 175-301.

Hooijer DA. 1952. Notes on the dentition of the golden monkey Rhinopithecus. J. Mammology 33:258-260.

Hrdlička A. 1907. Anatomical observations on a
TABLE 3. Incidence of M's in the Cebidae

\begin{tabular}{lccc}
\hline \multicolumn{1}{c}{ Genus } & $\begin{array}{c}\text { Number of } \\
\text { Specimens }\end{array}$ & M4 & Percent \\
\hline Lagothrix $^{1}$ & 94 & 0 & 0.00 \\
Brachyteles $^{1}$ & 25 & 0 & 0.00 \\
Ateles $^{1}$ & 232 & 7 & 3.00 \\
Ateles $^{8}$ & 612 & 6 & 0.98 \\
Saimiri $^{1}$ & 110 & 1 & 0.90 \\
Saimiri $^{8}$ & 100 & 1 & 0.10 \\
Cebus $^{1}$ & 651 & 4 & 0.60 \\
Alouatta $^{1}$ & 787 & 3 & 0.40 \\
Alouatta $^{8}$ & 956 & 3 & 0.31 \\
Cacajao $^{1}$ & 23 & 0 & 0.00 \\
Pithecia $^{1}$ & 155 & 0 & 0.00 \\
Callicebus $^{1}$ & 122 & 0 & 0.00 \\
Aotus $^{1}$ & 10 & 0 & 0.00 \\
\hline
\end{tabular}

${ }^{1}$ Miles and Grigson (1990) $\left(\mathrm{M}^{4}\right.$ and $\left.\mathrm{M}_{4}\right)$

${ }^{8}$ Krapp and Lampel (1973) $\left(\mathrm{M}^{4}\right.$ and $\left.\mathrm{M}_{4}\right)$

collection of orang skulls from Western Borneo. Proc US Natl Mus 31:539-568

Jungers LJ, Gingerich PD. 1980. Supernumerary molars in Anthropoidea, Adapidae, and Archaeolemur: Implications for primate homologies. Am J Phys Anthropol 52:1-5.

Krapp F, Lampel G. 1973. Zahnanomalien bei Altweltaffen (Catarrhina). Rev suisse Zool 80:83150.

Lavelle CLB, Moore WL. 1973. The incidence of agenesis and polygenesis in the primate dentition. Am J Phys Anthropol 38:671-680.

Miles AEW, Grigson C. 1990. Colyer's variations and diseases of the teeth of animals. Cambridge: Cambridge University Press.

Schultz AH. 1936. The eruption and decay of the permanent teeth in primates. Am J Phys Anthropol 19:489-581.

Selenka E. 1898. Rassen, Schadel und Bezahnung des Orangutan. Menschenaffen (Anthropomorphae). Studien uber Entwicklung und Schadelbau. Wiesbaden: CW Kreidels Verlag.

Sirianni JE, Swindler DR. 1985. Growth and development of the pigtailed macaque. Boca Raton: CRC Press, Inc.

Swindler, DR. 2002. Primate dentition: an introduction to the teeth of non-human primates. Cambridge: Cambridge University Press.

Winkler LA, Swindler DR. 1993. Report: Presence of a connate tooth in a neonate chimpanzee. Dental Anthropology Newsletter 8:9. 